\title{
Efficacy of Dulaglutide as a First Injectable Option for Patients with Type 2 Diabetes: A Post-Hoc Pooled Analysis
}

Hiren Patel (D) - Kashif Munir · Sindee Sutherland · Chrisanthi A. Karanikas •

Manige Konig

Received: August 12, 2019 / Published online: October 11, 2019

(C) The Author(s) 2019

\section{ABSTRACT}

Introduction: The ADA-EASD consensus report recommends using glucagon-like peptide-1 receptor agonists (GLP-1RAs) as the first injectable therapy prior to basal insulin in most patients with type 2 diabetes (T2D) not at glycemic goals after oral anti-hyperglycemia medications $(\mathrm{OH})$. The objective of this analysis was to assess the glycemic efficacy of once-weekly dulaglutide $1.5 \mathrm{mg}$ in patients with T2D when added on a background of commonly used $\mathrm{OH}$ regimens.

Methods: Patients from seven phase 3 AWARD [Assessment of Weekly AdministRation of LY2189265 (Dulaglutide) in Diabetes] trials,

Enhanced digital features To view enhanced digital features for this article go to https://doi.org/10.6084/ m9.figshare.9918719.

Electronic supplementary material The online version of this article (https://doi.org/10.1007/s13300019-00709-9) contains supplementary material, which is available to authorized users.

H. Patel $(\bowtie) \cdot$ C. A. Karanikas · M. Konig Eli Lilly and Company, Indianapolis, IN, USA e-mail: hpatel@lilly.com

K. Munir

Division of Endocrinology, Diabetes and Nutrition, University of Maryland School of Medicine,

Baltimore, MD, USA

S. Sutherland

Sutherland Consulting, Inc., Indianapolis, IN, USA where once-weekly dulaglutide $1.5 \mathrm{mg}$ was added to OHs, were pooled into the following categories based on $\mathrm{OH}$ regimens: metformin (MET), sulfonylurea (SU), MET + SU, MET + pioglitazone, and MET + SGLT2i. Change from baseline in glycated hemoglobin A1c (HbA1c), fasting serum glucose and body weight, proportion of patients reaching target $\mathrm{HbA} 1 \mathrm{c}<7 \%$, and safety parameters were assessed.

Results: A total of 1784 patients treated with once-weekly dulaglutide $1.5 \mathrm{mg}$ were included in this analysis. Baseline characteristics of the overall population were (mean \pm standard deviation): age, $55.4 \pm 9.8$ years, HbA1c: $8.2 \pm 1.0 \%$, body mass index: $31.4 \pm 5.4 \mathrm{~kg} / \mathrm{m}^{2}$, duration of diabetes: $8.0 \pm 5.6$ years, and 878 $(49.2 \%)$ were female. At 6 months, the addition of once-weekly dulaglutide $1.5 \mathrm{mg}$ to various $\mathrm{OH}$ regimens significantly reduced $\mathrm{HbA1c}$ $(-1.3$ to $-1.6 \%)$ and fasting blood glucose $(-29$ to $-45 \mathrm{mg} / \mathrm{dl})$ from baseline in all groups $(p<0.001)$, with $39-61 \%$ and $52-76 \%$ of these patients achieving HbA1c targets of $\leq 6.5 \%$ and $<7 \%$, respectively. Significant reductions in body weight ( -0.8 to $-2.9 \mathrm{~kg}$ ) were also observed in all groups $(p<0.001)$. Nausea, vomiting, and diarrhea were reported by $10-35 \%, 4-19 \%$, and $6-28 \%$ of patients, respectively. Severe hypoglycemia occurred in one patient (MET + SU).

Conclusion: The addition of a once-weekly GLP-1RA, dulaglutide, demonstrated clinically 
meaningful HbA1c reduction in patients with T2D on different background $\mathrm{OH}$ regimens, making it an effective first injectable option.

Funding: Eli Lilly and Company.

Keywords: Dulaglutide; GLP-1 receptor agonist; Oral antidiabetic medication; Type 2 diabetes

\section{INTRODUCTION}

Metformin, along with diet and exercise, is universally accepted as first-line oral hypoglycemic $(\mathrm{OH})$ therapy for patients with type 2 diabetes (T2D). Additional OHs, such as sulfonylureas (SUs), thiazolidinediones (TZDs), dipeptidyl peptidase-4 inhibitors (DPP4is), or sodium glucose co-transporter-2 inhibitors (SGLT2is), are often added sequentially as needed for management of persistent hyperglycemia. Due to the progressive nature of T2D, the majority of patients eventually require the addition of injectable therapy, either insulin or glucagon-like peptide-1 receptor agonist (GLP1RA), to $\mathrm{OH}$ to reach target glycemic control [1].

Although insulin is efficacious in lowering glucose, there is 'psychological insulin resistance' that occurs in both clinicians and patients when intensifying an $\mathrm{OH}$ regimen with insulin [2]. Time needed for proper patient education on insulin therapy, frequent glucose monitoring requirements, hypoglycemia risk, and weight gain are common clinician-related factors associated with this phenomenon. In addition, fear of needles, apprehension about injecting, concerns about weight gain, psychologic feelings such as "insulin is the last treatment resort" and "insulin seen as evidence for personal failure," and myths such as "insulin itself causes the long-term risks of diabetes like amputation or vision loss" are common barriers observed in patients [3]. A large retrospective study in the UK revealed that patients with T2D spend $>7$ years with their glycated hemoglobin A1c (HbA1c) > 7\% before initiating insulin [4]. Moreover, the majority of patients who have initiated basal insulin still fail to reach the relevant glycemic goals. In a US-based real-world study, $72 \%$ and $73 \%$ of patients who initiated basal insulin failed to reach an HbA1c target of $<7 \%$ after 6 months and 1 year, respectively [5]. Poor glycemic control after basal insulin initiation in patients with T2D is often attributed to suboptimal insulin titration [6]. Despite this, basal insulin continues to be a preferred option over GLP-1RAs in $73 \%$ of US patients with T2D who initiate an injectable glucoselowering therapy [7].

GLP-1RAs are effective in lowering both fasting and post-prandial glucose levels, with low risk of hypoglycemia, via their glucose-dependent insulin secretion and glucagon suppression, along with delaying gastric emptying [1]. Their satiety-causing and anorexigenic properties lead to modest weight loss $[8,9]$. Furthermore, long-acting GLP-1RAs such as liraglutide, semaglutide, albiglutide, and dulaglutide have demonstrated cardiovascular risk reduction when added to standard-of-care therapies [10-13]. GLP-1RAs are sometimes associated with gastrointestinal adverse reactions such as nausea, vomiting, and diarrhea for the initial few weeks after introduction with diminishing prevalence after repeated use [14]. Weekly GLP-1RAs have the advantage of a lower injection burden for patients compared with daily administration of basal insulin.

In a recent meta-analysis comparing the addition of GLP-1RAs and insulins to OHs, GLP1RAs resulted in statistically significant reductions in HbA1c (absolute mean difference, $0.12 \% ; p<0.001$ ) and body weight (absolute mean difference, $3.71 \mathrm{~kg} ; p<0.001$ ) compared with insulin [15]. The 2019 American Diabetes Association (ADA) Standards of Care recommend considering GLP-1RAs as first injectable therapy over insulin in a majority of patients with T2D when OHs are not sufficient [1]. This recommendation aligns with the current American Association of Clinical Endocrinologists (AACE) algorithm, which encourages the use of GLP-1RAs over other glucose-lowering medications, including basal insulin [16].

Dulaglutide is a once-weekly GLP-1RA, approved for the treatment of T2D in the US and EU [17, 18]. The AWARD [Assessment of Weekly Administration of LY2189265 (Dulaglutide) in Diabetes] clinical trial program included ten phase 3 trials with 6777 T2D 
patients. Across the AWARD program, treatment with dulaglutide $1.5 \mathrm{mg}$ resulted in $\mathrm{HbA1c}$ changes from baseline ranging from -0.8 to $-1.6 \%$, changes in fasting blood glucose from +23.1 to $-44.9 \mathrm{mg} / \mathrm{dl}$, and changes in body weight from -0.9 to $-2.9 \mathrm{~kg}$ in adults with T2D. Changes observed with the $0.75 \mathrm{mg}$ dose were -0.7 to $-1.6 \%,+17.7$ to $-34.0 \mathrm{mg} / \mathrm{dl}$, and +0.2 to $-2.6 \mathrm{~kg}$, respectively [19-28]. It is available in an auto-injector with a pre-attached hidden needle and provides dose confirmation to the patient with an audible click [29]. In a device study that included 211 injection-naïve patients with T2D, 99\% of patients trained to use the device were successfully able to complete the administration steps and $97 \%$ of patients were willing to use the device again [30].

The treatment effects of GLP-1RAs vary depending on the concomitant medication used. Therefore, a comprehensive understanding of the efficacy and safety of GLP-1RAs added on to background OHs is required to effectively implement the ADA and AACE recommendations. The objective of this pooled post hoc analysis was to assess the glycemic efficacy of dulaglutide $1.5 \mathrm{mg}$ when added on to commonly used background $\mathrm{OH}$ regimens in patients with T2D.

\section{METHODS}

\section{Patient Pooling Approach}

In this post hoc analysis, data from all global phase 3 clinical trials from the AWARD program where dulaglutide was assessed on the background of various $\mathrm{OH}$ regimens were pooled. Depending on the background OHs used in the AWARD program and length of each trial, data for five commonly used $\mathrm{OH}$ regimes could be pooled to have a sufficient sample size to perform efficacy and safety evaluations at 6 months. Background $\mathrm{OH}$ regimens that were evaluable included metformin (MET) from AWARD-5, AWARD-6, and AWARD-CHN2, glimepiride (SU) from AWARD-8 and AWARDCHN2, MET + SU from AWARD-2 and AWARD$\mathrm{CHN} 2$, MET and pioglitazone (MET + PIO) from AWARD-1, and MET + SGLT-2i from AWARD-10.

Individual trial designs and results have been previously published [19-28, 31]. Only patients treated with dulaglutide $1.5 \mathrm{mg}$ were included in this pooled analysis since the dulaglutide $0.75 \mathrm{mg}$ dose was not included in all aforementioned AWARD trials. Since the objective of this pooled analysis was to assess the efficacy and safety of dulaglutide when added to different $\mathrm{OH}$ regimens, comparator arms were not pooled. All original studies were conducted in accordance with the International Conference on Harmonisation Guidelines for Good Clinical Practice and the Declaration of Helsinki. Patients provided signed informed consent, and all protocols were approved by local ethics review boards.

\section{Statistical Analyses}

This analysis assessed the efficacy and safety of once-weekly dulaglutide $1.5 \mathrm{mg}$ in patients with T2D by background $\mathrm{OH}$ regimens (MET, SU, $\mathrm{MET}+\mathrm{SU}, \mathrm{MET}+\mathrm{PIO}$, and MET + SGLT-2i). Analyses were performed on an intent-to-treat (ITT) population (efficacy measures) or safety population (safety measures). All analyses were conducted at either 24 weeks (AWARD-8, AWARD-10) or 26 weeks (AWARD-1, AWARD-2, AWARD-5, AWARD-6, AWARD-CHN2), hereafter referred to as 6 months for the combined studies. Efficacy measures of change from baseline in $\mathrm{HbA1c}$, fasting plasma glucose, and body weight were analyzed using ANCOVA, with baseline value and treatment as continuous covariates. Efficacy measures did not include results obtained after post-rescue therapy. The last observation was carried forward (LOCF) for missing data at 6 months. Descriptive statistics were used for assessment of the proportion of patients achieving HbA1c targets of $<7 \%$ and $\leq 6.5 \%$ using the ITT population. Safety measures included all observations of hypoglycemia and gastrointestinal adverse events during the study period up to 6 months. Data are presented as least square mean (LSM) and 95\% confidence interval (CI), mean \pm standard deviation (SD), or number of patients $(n)$ and percent. Due to 
the post hoc nature of this analysis, statistical power was not calculated.

\section{RESULTS}

\section{Baseline Characteristics}

A total of 1784 patients with T2D treated with once-weekly dulaglutide $1.5 \mathrm{mg}$ were included in this analysis. These patients were categorized into the following $\mathrm{OH}$ regimens: MET $(N=712$; $39.9 \%), \quad$ SU $\quad(N=270 ; \quad 15.1 \%), \quad \mathrm{MET}+\mathrm{SU}$ $(N=390 ; 21.9 \%)$, MET + PIO $(N=279 ; 15.6 \%)$, and MET + SGLT-2i $(N=133 ; 7.5 \%)$. Baseline characteristics for subgroups of individual $\mathrm{OH}$ regimens and overall population are summarized in Table 1 . The mean \pm SD baseline characteristics of the overall population treated with dulaglutide $1.5 \mathrm{mg}$ were: age, $55.4 \pm 9.8$ years, HbA1c: $8.2 \pm 1.0 \%$, body mass index (BMI): $31.4 \pm 5.4 \mathrm{~kg} / \mathrm{m}^{2}$, and duration of diabetes: $8.0 \pm 5.6$ years; $878(49.2 \%)$ were female.

\section{Glycemic Efficacy with Dulaglutide $1.5 \mathrm{mg}$ by Background $\mathrm{OH}$ Regimens}

At 6 months, the addition of once-weekly dulaglutide $1.5 \mathrm{mg}$ to various $\mathrm{OH}$ regimens significantly reduced $\mathrm{HbA1c}$ from baseline in all groups $(p<0.001)$ (Fig. 1a). The largest reduction in HbA1c was observed in the MET + PIO subgroup [LSM $(95 \% \mathrm{CI})-1.6 \%(-1.7,-1.5)]$ with $61 \%$ and $76 \%$ of these patients achieving HbA1c targets of $\leq 6.5 \%$ and $<7 \%$, respectively. Similar HbA1c reductions were observed in the other $\mathrm{OH}$ groups, ranging from -1.3 to $-1.4 \%$, with $39-50 \%$ and $52-70 \%$ of patients achieving HbA1c targets of $\leq 6.5 \%$ and $<7 \%$, respectively (Fig. 1a).

The addition of dulaglutide $1.5 \mathrm{mg}$ to $\mathrm{OH}$ regimens also significantly reduced FPG from baseline in all groups at 6 months $(p<0.001)$ (Fig. 1b). The greatest reduction in FPG was observed in the MET + PIO subgroup [LSM $(95 \%$ CI $)-44.9 \mathrm{mg} / \mathrm{dl}(-48.8,-41.0)]$. Similarly, FPG reductions were observed in the other OGLM groups, ranging from -29 to $-39 \mathrm{mg} /$ dl (Fig. 1b).

\section{Change in Body Weight with Dulaglutide $1.5 \mathrm{mg}$ by Background OH Regimens}

At 6 months, dulaglutide $1.5 \mathrm{mg}$ added to $\mathrm{OH}$ regimens significantly reduced body weight from baseline in all groups $(p<0.001)$ (Fig. 2). The greatest reduction in body weight was observed in the MET + SGLT-2i group [LSM $(95 \% \mathrm{CI})-2.9 \mathrm{~kg}(-3.5,-2.3)]$, while patients on MET had a weight change of $-2.7 \mathrm{~kg}(-2.9$, $-2.4)$. Weight change from baseline in other $\mathrm{OH}$ regimens ranged from -0.8 to $-1.7 \mathrm{~kg}$.

\section{Safety}

\section{Hypoglycemia}

The overall incidence of total, documented symptomatic, and nocturnal hypoglycemia events was low (Supplemental Table 1). The highest rate of total, documented symptomatic, and nocturnal hypoglycemia events was observed in patients from the MET + SU group [plasma glucose $\leq 70 \mathrm{mg} / \mathrm{dl}$ : 170 patients (43.6\%), 104 patients $(26.7 \%)$, and 64 patients (16.4\%); plasma glucose $<54 \mathrm{mg} / \mathrm{dl}: \quad 56$ patients (14.4\%), 34 patients (8.7\%), and 17 patients $(4.4 \%)$, respectively]. One severe hypoglycemia event was reported (MET + SU subgroup).

\section{Other Adverse Events}

The complete safety profile for each study was previously reported [20-23, 27, 28, 31]. Overall, nausea, vomiting, and diarrhea were reported by $10-35 \%, 4-19 \%$, and $6-28 \%$ of patients, respectively (Supplemental Table 2). The highest number of events was reported from the MET + PIO group. The lowest number of events was reported from the SU group for nausea and vomiting and from the MET + SGLT-2i group for diarrhea.

\section{DISCUSSION}

GLP-1RAs are an effective injectable treatment option with benefits beyond just glucose lowering. The recent recommendation from ADA 
Table 1 Baseline demographics by $\mathrm{OH}$ subgroup

\begin{tabular}{|c|c|c|c|c|c|c|}
\hline & $\begin{array}{l}\text { MET } \\
N=712\end{array}$ & SU $N=270$ & $\begin{array}{l}\text { MET }+ \text { SU } \\
N=390\end{array}$ & $\begin{array}{l}\text { MET + PIO } \\
N=279\end{array}$ & $\begin{array}{l}\text { MET + SGLT- } \\
2 \mathrm{i} N=133\end{array}$ & $\begin{array}{l}\text { Overall } \\
N=1784\end{array}$ \\
\hline Sex, female & $363(51.0)$ & $148(54.8)$ & $191(49.0)$ & $116(41.6)$ & $60(45.1)$ & $878(49.2)$ \\
\hline Age, years & $54.3 \pm 10.0$ & $57.1 \pm 10.1$ & $55.9 \pm 9.14$ & $55.7 \pm 9.7$ & $56.1 \pm 9.4$ & $55.4 \pm 9.8$ \\
\hline HbAlc, \% & $8.1 \pm 1.0$ & $8.4 \pm 0.7$ & $8.3 \pm 1.1$ & $8.1 \pm 1.3$ & $8.0 \pm 0.6$ & $8.2 \pm 1.0$ \\
\hline $\mathrm{HbAlc}, \mathrm{mmol} / \mathrm{mol}$ & $65.0 \pm 10.1$ & $66.1 \pm 8.1$ & $68.3 \pm 11.8$ & $65.0 \pm 14.7$ & $63.9 \pm 7.1$ & $66.1 \pm 11.3$ \\
\hline $\begin{array}{l}\text { Fasting blood glucose, } \\
\mathrm{mg} / \mathrm{dl}\end{array}$ & $170.8 \pm 49.9$ & $176.8 \pm 52.2$ & $168.4 \pm 48.6$ & $162.1 \pm 55.7$ & $159.2 \pm 31.6$ & $168.9 \pm 50.0$ \\
\hline $\begin{array}{l}\text { Fasting blood glucose, } \\
\mathrm{mmol} / \mathrm{l}\end{array}$ & $9.5 \pm 2.8$ & $9.8 \pm 2.9$ & $9.4 \pm 2.7$ & $9.0 \pm 3.1$ & $8.8 \pm 1.8$ & $9.4 \pm 2.8$ \\
\hline Weight, kg & $87.8 \pm 18.3$ & $83.0 \pm 16.4$ & $81.5 \pm 17.6$ & $96.2 \pm 19.6$ & $93.0 \pm 20.2$ & $87.4 \pm 18.9$ \\
\hline \multicolumn{7}{|l|}{ Weight at baseline } \\
\hline$<90 \mathrm{~kg}$ & $406(57.0)$ & $191(70.7)$ & $273(70.0)$ & $110(39.4)$ & $61(45.9)$ & $1041(58.4)$ \\
\hline$\geq 90 \mathrm{~kg}$ & $306(43.0)$ & $79(29.3)$ & $117(30.0)$ & $169(60.6)$ & $72(45.1)$ & $743(41.6)$ \\
\hline BMI, $\mathrm{kg} / \mathrm{m}^{2}$ & $31.5 \pm 5.2$ & $30.4 \pm 5.2$ & $29.9 \pm 5.3$ & $33.1 \pm 5.3$ & $33.0 \pm 5.6$ & $31.4 \pm 5.4$ \\
\hline \multicolumn{7}{|l|}{ BMI at baseline } \\
\hline$<25 \mathrm{~kg} / \mathrm{m}^{2}$ & $67(9.4)$ & $40(14.8)$ & $77(19.7)$ & $17(6.1)$ & $8(6.0)$ & $209(11.7)$ \\
\hline$\geq 25$ and $<30 \mathrm{~kg} / \mathrm{m}^{2}$ & $231(32.4)$ & $98(36.3)$ & $139(35.6)$ & $74(26.5)$ & $41(30.8)$ & $583(32.7)$ \\
\hline$\geq 30$ and $<35 \mathrm{~kg} / \mathrm{m}^{2}$ & $234(32.9)$ & $86(31.9)$ & $111(28.5)$ & $84(30.1)$ & $36(27.1)$ & $551(30.9)$ \\
\hline$\geq 35 \mathrm{~kg} / \mathrm{m}^{2}$ & $180(25.3)$ & $46(17.0)$ & $63(16.2)$ & $104(37.3)$ & $48(36.1)$ & $441(24.7)$ \\
\hline $\begin{array}{l}\text { Duration of diabetes, } \\
\text { years }\end{array}$ & $6.8 \pm 5.4$ & $7.8 \pm 5.2$ & $9.3 \pm 5.9$ & $8.8 \pm 5.6$ & $9.4 \pm 5.8$ & $8.0 \pm 5.6$ \\
\hline \multicolumn{7}{|l|}{ Duration of diabetes group } \\
\hline$<5$ years & $290(40.7)$ & $82(30.4)$ & $89(22.8)$ & $71(25.4)$ & $25(18.8)$ & $557(31.2)$ \\
\hline$\geq 5$ and $<10$ years & $248(34.8)$ & $104(38.5)$ & $148(37.9)$ & $95(34.1)$ & $53(39.8)$ & $648(36.3)$ \\
\hline$\geq 10$ years & $174(24.4)$ & $84(31.1)$ & $153(39.2)$ & $113(40.5)$ & $55(41.4)$ & $579(32.5)$ \\
\hline
\end{tabular}

Data are presented as mean \pm SD or $n$ (\%)

and EASD suggests using GLP-1RAs over insulins after $\mathrm{OHs}$ as preferred first injectable in patients with T2D who need additional glycemic control. GLP-1RAs with proven cardiovascular $(\mathrm{CV})$ benefits are recommended in patients with established atherosclerotic $\mathrm{CV}$ disease following metformin therapy. Additionally, patients who have compelling need to minimize weight gain or promote weight loss should choose GLP-1RAs with good efficacy for weight loss. This recommendation will likely increase the use of this class [1]. This report will help physicians make an evidence-based utilization of a weekly GLP-1RA, dulaglutide, when added to various $\mathrm{OH}$ regimens for patients with T2D. 

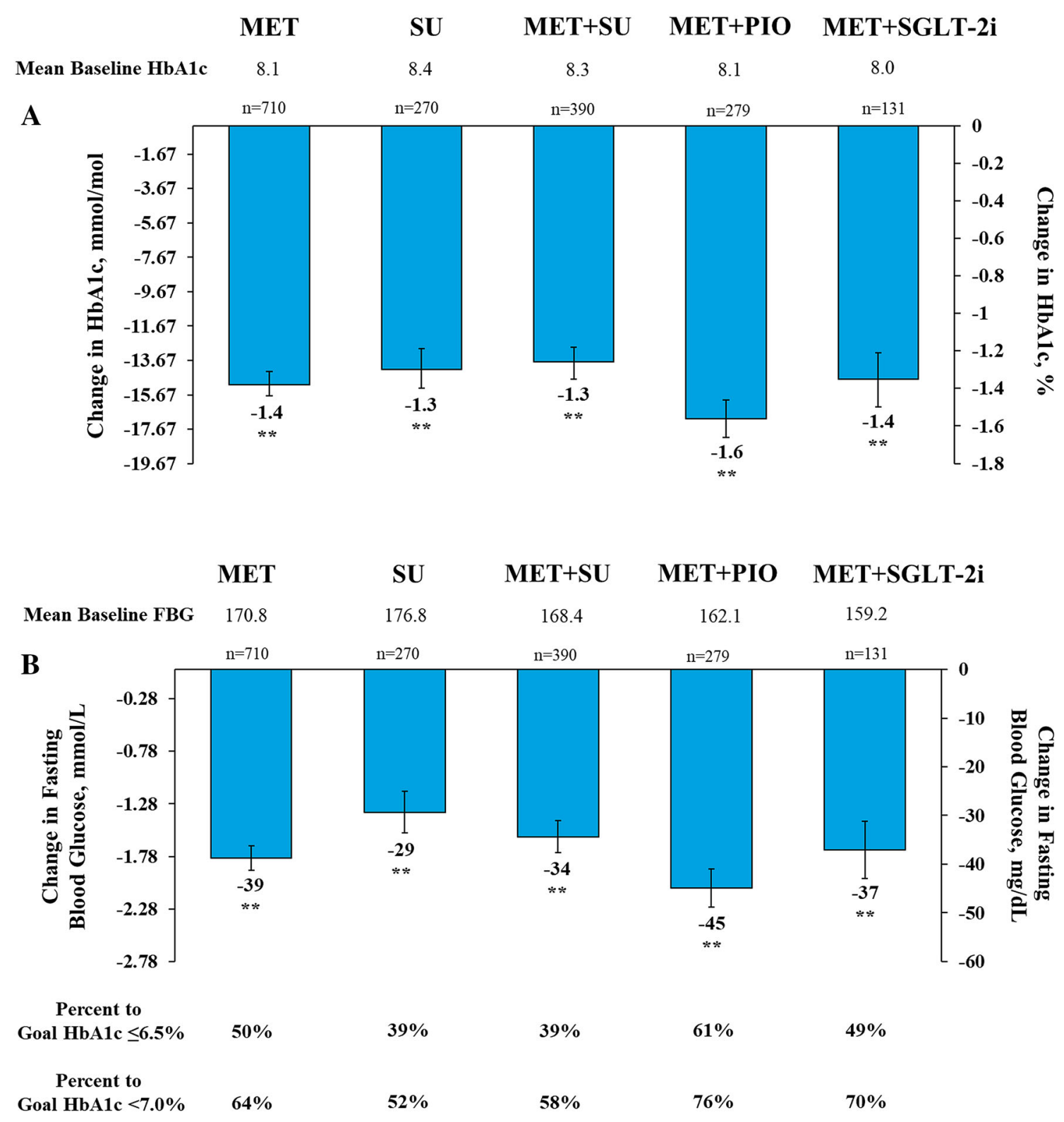

Data are presented as LSM $(95 \% \mathrm{CI}) ; * * \mathrm{p}<0.001$ versus baseline

Fig. 1 Glycemic efficacy of dulaglutide $1.5 \mathrm{mg}$ by $\mathrm{OH}$ subgroup at 6 months. Data are presented as LSM (95\% CI); ${ }^{* *} p<0.001$ versus baseline

In this pooled analysis of seven AWARD phase 3 clinical trials, dulaglutide $1.5 \mathrm{mg}$ lowered HbA1c from -1.3 to $-1.6 \%$ after 6 months when added to commonly used $\mathrm{OH}$ regimens. This was accompanied by modest weight loss ranging from -0.8 to $-2.9 \mathrm{~kg}$. The $\mathrm{OH}$ regimens evaluated in this report, i.e., MET,
$\mathrm{SU}, \quad \mathrm{MET}+\mathrm{SU}, \quad \mathrm{MET}+\mathrm{PIO}$, and $\mathrm{MET}+$ SGLT2i, are commonly used therapies for T2D management [1].

The smallest reduction in HbA1c $(-1.3 \%)$ was observed in the two groups where SU was used as background medication. The weightlowering effects of dulaglutide were also 


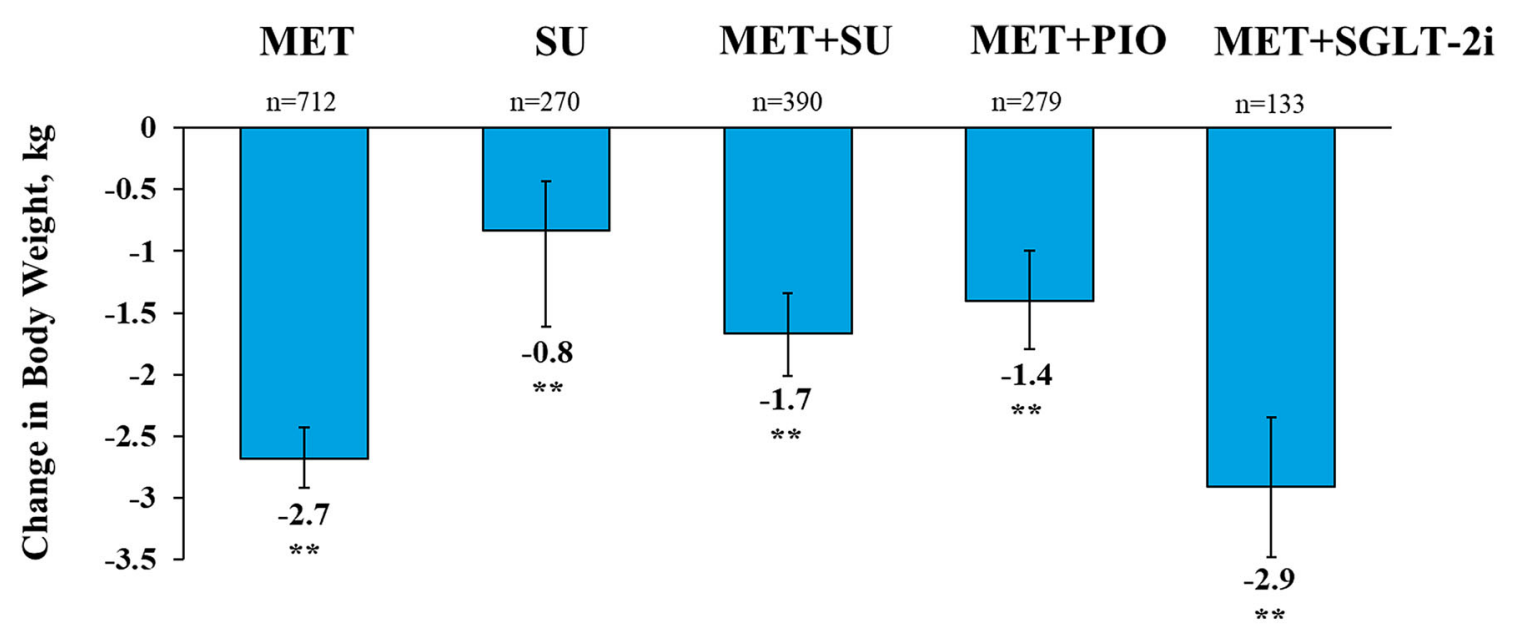

Data are presented as LSM $(95 \% \mathrm{CI}) ;{ }^{*} \mathrm{p}<00.001$ versus baseline

Fig. 2 Change from baseline in body weight with dulaglutide $1.5 \mathrm{mg}$ by $\mathrm{OH}$ subgroup at 6 months. Data are presented as LSM (95\% CI); ${ }^{* *} p<0.001$ versus baseline

diminished in these two groups. Moreover, this regimen was associated with a larger number of hypoglycemia events. Overall, there was only one case of severe hypoglycemia, which was observed in the group with MET + SU as background therapy. Hence, it is advisable to lower the dose of SU when adding dulaglutide [17] and educate patients on symptoms of hypoglycemia. The lower HbA1c reduction observed in these groups may be due to the overlap in the insulin secretion pathway used by SU and GLP1RA classes of medications [32]. The greatest reduction in HbA1c $(-1.6 \%)$ was observed in patients on a background $\mathrm{OH}$ regimen of MET + PIO. It could be hypothesized that the improvements in insulin resistance seen with TZD [33] could complement the insulin secretion mechanism with this combination. Again, the weight loss effect of dulaglutide seemed to be attenuated because of the weight-gaining properties of TZD [34]. Likewise, in the SUSTAIN-2 study, the addition of a weekly GLP1RA, semaglutide $1.0 \mathrm{mg}$, to background therapy of MET \pm TZD resulted in a similar HbA1c reduction $(-1.6 \%)$ at 56 weeks [35].

There is an increasing consensus on combining SGLT2i and GLP-1RAs to maximize the metabolic benefits of these classes [1]. If drugs from either class do not provide sufficient glycemic control, the ADA/EASD consensus statement encourages combining them in patients with T2D and cardiovascular disease and/or patients who needed to minimize weight gain or promote weight loss [1]. This guidance was reiterated by recent guidelines published by the European Society of Cardiology developed in collaboration with the EASD [36]. In this report, patients on background MET \pm SGLT2i demonstrated a mean reduction in $\mathrm{HbA1c}$ of $-1.4 \%$ and a reduction in body weight of $-2.9 \mathrm{~kg}$. In the DURATION-8 trial, significant reductions in HbA1c $(-2.0 \%)$ and body weight $(-3.8 \mathrm{~kg})$ were observed in patients treated with once-weekly GLP-1RA exenatide plus dapagliflozin [37]. The greater HbA1c and weight reductions observed in DURATION-8 may be, in part, due to the fact that patients started both treatments (exenatide and dapagliflozin) simultaneously, whereas patients from AWARD-10 were already on a stable dose of SGLT2i when they initiated dulaglutide [23, 37]. In addition, patients from DURATION-8 had a higher baseline HbA1c (9.3\%); thus, a greater reduction would be expected. In SUSTAIN 9, significant reductions in $\mathrm{HbA1c}(-1.5 \%)$ and body weight $(-4.7 \mathrm{~kg})$ were observed in patients treated with semaglutide $1.0 \mathrm{mg}$ added onto an SGLT2i [38]. Notably, reports of hypoglycemia in patients treated with this combination were low in all three studies [23, 37, 38]. 
Although agents from both of these classes have demonstrated varieties of cardiovascular benefits individually $[10,11,39,40]$, there is currently no evidence that this combination could synergize these outcomes.

Limitations of this study include the post hoc nature of this analysis. Additionally, the durations of the studies in the present analysis were limited to 6 months, which may not represent the effects of long-term use of dulaglutide. No statistical analysis was performed to compare the treatment effect between groups of different OHs. However, this analysis was intended to provide additional insight for clinicians when $\mathrm{OH}$ therapy alone does not suffice and treatment intensification is required with an injectable.

\section{CONCLUSIONS}

In patients with $\mathrm{T} 2 \mathrm{D}$ on different $\mathrm{OH}$ regimens requiring intensification of treatment, onceweekly dulaglutide $1.5 \mathrm{mg}$ demonstrated clinically meaningful glycemic control, making it an effective first injectable option for a wide range of patients.

\section{ACKNOWLEDGEMENTS}

Funding. Funding of this study and for the journal's Rapid Service Fee is provided by Eli Lilly and Company.

Authorship. All named authors meet the International Committee of Medical Journal Editors (ICMJE) criteria for authorship for this article, take responsibility for the integrity of the work as a whole, and have given their approval for this version to be published.

Authorship Contributions. S.S. was responsible for the statistical considerations in the analysis. H.P. and M.K. are the guarantors of this work and, as such, take responsibility for the integrity of the data and the accuracy of the data analysis. All authors contributed to the design of this post hoc analysis and participated in critical reviewing and interpreting the data for the manuscript.

Prior Presentation. An abstract of this study has been accepted for publication at the American Diabetes Association 79th Scientific Sessions, held June 7-11, 2019, in San Francisco, California.

Disclosures. Kashif Munir has nothing to disclose. Sindee Sutherlandis was independently contracted by Eli Lilly and Company. Hiren Patel is an employee and shareholder of Eli Lilly and Company. Chrisanthi A. Karanikas is an employee and shareholder of Eli Lilly and Company. Manige Konig is an employee and shareholder of Eli Lilly and Company.

Compliance with Ethics Guidelines. All original studies were conducted in accordance with the International Conference on Harmonisation Guidelines for Good Clinical Practice and the Declaration of Helsinki. Patients provided signed informed consent and all protocols were approved by local ethical review boards.

Data Availability. The datasets during and/ or analyzed during the current study are available from the corresponding author on reasonable request.

Open Access. This article is distributed under the terms of the Creative Commons Attribution-NonCommercial 4.0 International License (http://creativecommons.org/licenses/ by-nc/4.0/), which permits any noncommercial use, distribution, and reproduction in any medium, provided you give appropriate credit to the original author(s) and the source, provide a link to the Creative Commons license, and indicate if changes were made.

\section{REFERENCES}

1. American Diabetes Association. Standards of medical care in diabetes-2019. Diabetes Care. 2019;42(Suppl 1):S1-193. 
2. Brod M, Kongsø JH, Lessard S, Christensen TL. Psychological insulin resistance: patient beliefs and implications for diabetes management. Qual Life Res. 2009;18(1):23-32.

3. Brod M, Alolga SL, Meneghini L. Barriers to initiating insulin in type 2 diabetes patients: development of a new patient education tool to address myths, misconceptions and clinical realities. Patient. 2014;7(4):437-50.

4. Khunti K, Millar-Jones D. Clinical inertia to insulin initiation and intensification in the UK: a focused literature review. Prim Care Diabetes. 2017;11(1): 3-12.

5. Carls G, Huynh J, Tuttle E, Yee J, Edelman SV. Achievement of glycated hemoglobin goals in the us remains unchanged through 2014. Diabetes Ther. 2017;8(4):863-73.

6. Mocarski M, Yeaw J, Divino V, et al. Slow titration and delayed intensification of basal insulin among patients with type 2 diabetes. J Manag Care Spec Pharm. 2018;24(4):390-400.

7. Yu M, Mody R, Landó LF, et al. Characteristics associated with the choice of first injectable therapy among us patients with type 2 diabetes. Clin Ther. 2017;39(12):2399-408.

8. van Bloemendaal L, IJzerman RG, Ten Kulve JS, et al. GLP-1 receptor activation modulates appetiteand reward-related brain areas in humans. Diabetes. 2014;63(12):4186-96.

9. Shah M, Vella A. Effects of GLP-1 on appetite and weight. Rev Endocr Metab Disord. 2014;15(3): 181-7.

10. Marso SP, Bain SC, Consoli A. Semaglutide and cardiovascular outcomes in patients with type 2 diabetes. N Engl J Med. 2016;375(19):1834-44.

11. Marso SP, Daniels GH, Brown-Frandsen K. Liraglutide and cardiovascular outcomes in type 2 diabetes. N Engl J Med. 2016;375(4):311-22.

12. Hernandez AF, Green JB, Janmohamed S. Albiglutide and cardiovascular outcomes in patients with type 2 diabetes and cardiovascular disease (Harmony Outcomes): a double-blind, randomised placebo-controlled trial. Lancet. 2018;392(10157): 1519-29.

13. Gerstein HC, Colhoun HM, Dagenais GR. Dulaglutide and cardiovascular outcomes in type 2 diabetes (REWIND): a double-blind, randomised placebocontrolled trial. Lancet. 2019;394(10193):121-30.

14. Bettge K, Kahle M, Abd El Aziz MS, Meier JJ, Nauck MA. Occurrence of nausea, vomiting and diarrhoea reported as adverse events in clinical trials studying glucagon-like peptide-1 receptor agonists: a systematic analysis of published clinical trials. Diabetes Obes Metab. 2017;19(3):336-47.

15. Abd El Aziz MS, Kahle M, Meier JJ, Nauck MA. A meta-analysis comparing clinical effects of short- or long-acting GLP-1 receptor agonists versus insulin treatment from head-to-head studies in type 2 diabetic patients. Diabetes Obes Metab. 2017;19(2): 216-27.

16. Garber AJ, Abrahamson MJ, Barzilay JI, et al. Consensus statement by the American Association of Clinical Endocrinologists and American College of Endocrinology on the comprehensive type 2 diabetes management algorithm 2018 executive summary. Endocr Pract. 2018;24(1):91-120.

17. Trulicity (2019) Rev Jan 2019. Indianapolis, IN: Lilly USA, LLC; 2019. http://uspl.lilly.com/trulicity/ trulicity.html\#pi Accessed 14 May 2019.

18. Trulicity (2018) Houten, The Netherlands: Eli Lilly and Company; 2018. https://www.ema.europa.eu/ documents/product-information/trulicity-epar-prod uct-information_en.pdf Accessed 4 Feb 2019.

19. Blonde L, Jendle J, Gross J, et al. Once-weekly dulaglutide versus bedtime insulin glargine, both in combination with prandial insulin lispro, in patients with type 2 diabetes (AWARD-4): a randomised, open-label, phase 3, non-inferiority study. Lancet. 2015;385(9982):2057-66.

20. Dungan KM, Povedano ST, Forst T, et al. Onceweekly dulaglutide versus once-daily liraglutide in metformin-treated patients with type 2 diabetes (AWARD-6): a randomised, open-label, phase 3, non-inferiority trial. Lancet. 2014;384(9951): 1349-57.

21. Dungan KM, Weitgasser R, Perez Manghi F, et al. A 24-week study to evaluate the efficacy and safety of once-weekly dulaglutide added on to glimepiride in type 2 diabetes (AWARD-8). Diabetes Obes Metab. 2016;18(5):475-82.

22. Giorgino F, Benroubi M, Sun JH, Zimmermann AG, Pechtner V. Efficacy and safety of once weekly dulaglutide versus insulin glargine in patients with type 2 diabetes on metformin and glimepiride (AWARD-2). Diabetes Care. 2015;38(12):2241-9.

23. Ludvik B, Frías JP, Tinahones FJ. Dulaglutide as addon therapy to SGLT2 inhibitors in patients with inadequately controlled type 2 diabetes (AWARD10): a 24 -week, randomised, double-blind, placebocontrolled trial. Lancet Diabetes Endocrinol. 2018;6(5):370-81. 
24. Pozzilli P, Norwood P, Jódar E, et al. Placebo-controlled, randomized trial of the addition of onceweekly glucagon-like peptide-1 receptor agonist dulaglutide to titrated daily insulin glargine in patients with type 2 diabetes (AWARD-9). Diabetes Obes Metab. 2017;19(7):1024-31.

25. Tuttle KR, Lakshmanan MC, Rayner B, et al. Dulaglutide versus insulin glargine in patients with type 2 diabetes and moderate-to-severe chronic kidney disease (AWARD-7): a multicentre, open-label, randomised trial. Lancet Diabetes Endocrinol. 2018;6(8):605-17.

26. Umpierrez G, Tofé Povedano S, Pérez Manghi F, Shurzinske L, Pechtner V. Efficacy and safety of dulaglutide monotherapy versus metformin in type 2 diabetes in a randomized controlled trial (AWARD-3). Diabetes Care. 2014;37(8):2168-76.

27. Wysham C, Blevins T, Arakaki R, et al. Efficacy and safety of dulaglutide added on to pioglitazone and metformin versus exenatide in type 2 diabetes in a randomized controlled trial (AWARD-1). Diabetes Care. 2014;37(8):2159-67.

28. Weinstock RS, Guerci B, Umpierrez G, Nauck MA, Skrivanek Z, Milicevic Z. Safety and efficacy of onceweekly dulaglutide versus sitagliptin after 2 years in metformin-treated patients with type 2 diabetes (AWARD-5): a randomized, phase III study. Diabetes Obes Metab. 2015;17(9):849-58.

29. Trulicity (2018) Indianapolis, IN: Lilly USA, LLC; 2018. http://pi.lilly.com/us/trulicity-highdose-aiifu.pdf. Accessed 14 Feb 2019.

30. Matfin G, Van Brunt K, Zimmermann AG, Threlkeld $\mathrm{R}$, Ignaut DA. Safe and effective use of the once weekly dulaglutide single-dose pen in injectionnaïve patients with type 2 diabetes. J Diabetes Sci Technol. 2015;9(5):1071-9.

31. Wang W, Nevárez L, Filippova E, et al. Efficacy and safety of once-weekly dulaglutide versus insulin glargine in mainly Asian patients with type 2 diabetes mellitus on metformin and/or a sulphonylurea: a 52-week open-label, randomized phase III trial. Diabetes Obes Metab. 2019;21(2):234-43.

32. Meloni AR, DeYoung MB, Lowe C, Parkes DG. GLP1 receptor activated insulin secretion from pancreatic $\beta$-cells: mechanism and glucose dependence. Diabetes Obes Metab. 2012;15(1):15-27.

33. Lebovitz HE, Banerji MA. Insulin resistance and its treatment by thiazolidinediones. Recent Prog Horm Res. 2001;56:194-265.

34. Fonseca V. Effect of thiazolidinediones on body weight in patients with diabetes mellitus. Am J Med. 2003;115(Suppl 8A):42S-8S.

35. Ahrén B, Masmiquel L, Kumar H, et al. Efficacy and safety of once-weekly semaglutide versus once-daily sitagliptin as an add-on to metformin, thiazolidinediones, or both, in patients with type 2 diabetes (SUSTAIN 2): a 56-week, double-blind, phase 3a, randomised trial. Lancet Diabetes Endocrinol. 2017;5(5):341-54.

36. Cosentino F, Grant PJ, Aboyans V, et al. ESC Guidelines on diabetes, pre-diabetes, and cardiovascular diseases developed in collaboration with the EASD: the task force for diabetes, pre-diabetes, and cardiovascular diseases of the European Society of Cardiology (ESC) and the European Association for the Study of Diabetes (EASD). Eur Heart J. 2019. https://doi.org/10.1093/eurheartj/ehz486.

37. Frías JP, Guja C, Hardy E, et al. Exenatide once weekly plus dapagliflozin once daily versus exenatide or dapagliflozin alone in patients with type 2 diabetes inadequately controlled with metformin monotherapy (DURATION-8): a 28 week, multicentre, double-blind, phase 3 , randomised controlled trial. Lancet Diabetes Endocrinol. 2016;4(12):1004-16.

38. Zinman B, Bhosekar V, Busch R, et al. Semaglutide once weekly as add-on to SGLT-2 inhibitor therapy in type 2 diabetes (SUSTAIN 9): a randomised, placebo-controlled trial. Lancet Diabetes Endocrinol. 2019;7(5):356-67.

39. Zinman B, Wanner C, Lachin JM, et al. Empagliflozin, cardiovascular outcomes, and mortality in type 2 diabetes. N Engl J Med. 2015;373(22): 2117-28.

40. Neal B, Perkovic V, Mahaffey KW, et al. Canagliflozin and cardiovascular and renal events in type 2 diabetes. N Engl J Med. 2017;377(7):644-57. 